IRA-International Journal of Education \& Multidisciplinary Studies

ISSN 2455-2526; Vol.10, Issue 03 (March, 2018)

Pg. no. 35-47.

Institute of Research Advances

http://research-advances.org/index.php/IJEMS

\title{
Computer Supported Collaborative Writing: Does it Work among ESL Learners?
}

\author{
Nur Hazirah Che Ithnin ${ }^{1 \#}$, Farhanahbinti Mohamad Fikray ${ }^{2} \&$ Noor Zainab Abdul Razak ${ }^{3}$ \\ ${ }^{1,2,3}$ Universiti Teknologi Malaysia, Johor, Malaysia. \\ \#corresponding author. \\ Type of Review: Peer Reviewed. \\ DOI: http://dx.doi.org/10.21013/jems.v10.n3.p3
}

\section{How to cite this paper:}

Ithnin, N., Fikray, F., Razak, N. (2018). Computer Supported Collaborative Writing: Does it Work among ESL Learners? IRA International Journal of Education and Multidisciplinary Studies (ISSN 2455-2526), 10(3), 35-47.doi: http://dx.doi.org/10.21013/jems.v10.n3.p3

(C) Institute of Research Advances.

\section{(cc) EY-NC}

This work is licensed under a Creative Commons Attribution-Non Commercial 4.0 International License subject to proper citation to the publication source of the work.

Disclaimer: The scholarly papers as reviewed and published by the Institute of Research Advances (IRA) are the views and opinions of their respective authors and are not the views or opinions of the IRA. The IRA disclaims of any harm or loss caused due to the published content to any party.

Institute of Research Advances is an institutional publisher member of Publishers Inter Linking Association Inc. (PILA-CrossRef), USA. The institute is an institutional signatory to the Budapest Open Access Initiative, Hungary advocating the open access of scientific and scholarly knowledge. The Institute is a registered content provider under Open Access Initiative Protocol for Metadata Harvesting (OAI-PMH).

The journal is indexed \& included in WorldCat Discovery Service (USA), CrossRef Metadata Search (USA), WorldCat (USA), OCLC (USA), Open J-Gate (India), EZB (Germany) Scilit (Switzerland), Airiti (China), Bielefeld Academic Search Engine (BASE) of Bielefeld University, Germany, PKP Index of Simon Fraser University, Canada. 


\begin{abstract}
This study examines the effectiveness of using Wiki as a platform to enhance EL learners' writing skill in English language. In particular, the aim of this research is to examine learners' performance in composing English language essays as well as to identify the challenges which the students faced throughout the process of writing through Wiki. This study involved the respondents from secondary school who were in Form 2 and it consists of three levels of language proficiency which the researchers have identified. Specifically, the research data is collected through writing assessments (pre-test and post-test). For pre-test and post-test, the website selected as a platform was ZOHO Wiki which is a free user friendly online server designed for collaborative writing. The data from pre-test and post-test was analysed according to the marks obtained. Particularly, the research findings showed that students positively show an encouraging improvement in their English language essays and writing skill. Besides, some challenges on the Wiki website and technological related issues that occurred during the process of Wiki mediated writing have also been identified such as difficulties in terms of Wiki tools software, technological related problem, collaborative writing issues, and other relevant challenges related to the research topic. In addition, the pedagogical implications, limitations as well as recommendations on the future research which are relevant to the present study are discussed and elaborated. In short, collaborative learning through Wiki provides learners with an interactive platform for writing English language composition.
\end{abstract}

Keywords: Collaboration, Computer support, Learning, Sentence structure, Tenses, Wiki, Writing skill

\title{
Introduction
}

The growth of technological instruments and globalization contribute to the creative and innovative development in many fields and areas especially in the field of education. This is portrayed by Deter, Cuthrell and Stapleston (2010) that technology is continuously evolving and this situation allows the incorporation of interactive learning environment in language classroom to fulfil the needs of the $21^{\text {st }}$ century students. Due to this circumstance, this research applied the integration of Computer-Supported Collaborative Writing through the use of Web 2.0 tools which allows users to socially connect, interact, and switch information between one another (Bragg, 2007).

Specifically, this research aims to encourage students' writing skill through the use of Wiki. Therefore, the focus should also be given to the atmosphere of writing lessons among ESL learners. English is one of the core subjects in the Malaysian education system, starting from primary level (Year 1 to Year 6) and secondary level (Form 1 to Form 5). Majority of these students will further their studies in the tertiary education and English language is a prerequisite if they want to be successful in their academic endeavour. Thus, it is essential for one to be able to master the four macro skills, namely listening, speaking, reading and writing at an early stage. Writing skills are given more emphasis as pupils need to undergo several examinations throughout the primary and secondary school year. In addition, most tests contain writing components and students need to have good writing skills to do well in examinations. In other words, learning to write and acquiring writing skills can be considered as an important foundation in a child's development and can pave the way for academic success in the future.

The National Writing Project and Nagin (2003:10) states that "Even the most accomplished writers say that writing is challenging, most notably because there is so much uncertainty embedded in the process of doing it. The writer doesn't always know beforehand where to begin, much less how to proceed." This demonstrates that writing is indeed a complex process. Therefore, it is of perennial interest for English language teachers to become aware of this matter and find ways in developing and improving students' writing.

In addition, Haifa al-Buainain (2006), emphasized that writing can be regarded as one of the toughest and exasperating aspect of language skills to be taught in ESL or EFL classroom. Thus, perceivably most teachers feel reluctant and demotivated as it comes to this subject. Besides that, he also states that, teachers often use of handouts and written instruction for writing tasks leads to boredom among students. According to Winkler and McCuen (1997) students possess negative assumptions and interpretation towards writing. Besides, they also have wrong assumption on writing where it must be 
consisted of long sentences, and detail focus needs to be given to the aspect of punctuation and grammar which make it more difficult for them to write perfectly.

Therefore, in this research, Wiki is presented as a means to improvise the teaching pedagogy that teachers usually apply in their classroom. Not only that, this research is also hoped to shed some lights on more interactive writing platform and activities which promote collaborative learning among ESL learners in Malaysia.

\section{Conceptual Framework}

The present study is grounded based on Vygotsky (1978) social cognitive theory. This theory highlights the importance social interactions between students through a specific mediated learning process. Particularly, the mediated learning experience means the necessity to have other party to channel and share knowledge so that it can be understood by all the participants within the group (Ashman \& Gillies, 2003). Not only that, this theory was further elaborated by William and Burden (1997) who suggest that in developing learners' skills and knowledge, assistance as well as communication between less proficient students with more capable users are necessary. Due to this circumstance, it is important to emphasize that learner centred learning leads to better non-threatening learning environment where students can possibly acquire more second language input through peer feedback and guidance.

In the present study, the concept of Vygotsky (1978) social cognitive theory of mediated learning experience is described extensively in depth based on Feuerstein (1990). It is said that, human can act as the mediator or platform for successful language learning. Specifically, this situation elaborates the notion of scaffolding in the second language lessons. Scaffolding aids ESL learners who face difficulties in mastering some language concept to gain peer advices through recruiting in assignment, task simplification, maintaining the learning goal, motivating each other to overcome frustration during task completion, and planning the arrangement of ideas throughout the learning process (Wood, Bruner, \& Ross, 1976). Therefore, by this way incapable learners will be able to internalize the language knowledge they acquired through more competent friends. Whereas, the high proficient learners will be able to strengthen the second language input through the cooperation with other learners in the collaborative-based assignments.

In this research, the researcher applied a framework adapted from Li, Chu, Ki and Woo (2012) in their research on collaborative writing through Wiki based on the Vygotsky (1978) theory of social cognitive that has been discussed earlier. Firstly, a Wiki based collaborative writing platforms are set up by using an online collaborative writing medium which is ZOHO Wiki. Through these means, the respondents of different language proficiency cooperate with each other to complete several writing tasks together. The writing tasks were done through the Wiki-based collaborative writing which was guided and instructed by the researcher in each of the sessions. Meanwhile, students facilitated and communicated collaboratively to complete essays in every task. In a way, the process of scaffolding and Vygotsky (1978) theory of learning is applied in this learning context. It is crucial to stress that all of the interaction either student-student or teacher-student that occur in this study were done through online medium.

This research is adapted from $\mathrm{Li}, \mathrm{Chu}, \mathrm{Ki}$ and Woo (2012) framework of collaborative writing through Wiki by incorporating Vygotsky (1978) theory of social cognitive learning. To this extent, the present study applied all of the stages need to be undergone by the students in collaborative writing process. The process includes group pre-writing, drafting, revising and editing which were done during the treatment session within two weeks. In the prewriting stage of collaborative writing, students brainstormed the ideas on what they will be writing. Then, the drafting stage needs the students to collaboratively expand and elaborate their ideas in depth. Plus, this stage focuses on the organisation and expansion of ideas instead of the grammatical structure. The next stage of revising comprises of three elements which are reread, re-organised and revise based on each other's comments of the content of the essay that has been written on the Wiki by correcting minor changes on the word choice or sentence structure. As for the last stage of editing, all of the students had to put the writing in the final form by looking closely at the linguistic and content correctness in their essay. Only then, the essay can be published as the final product for each of the session during the treatment. The description of each stage in the collaborative writing 
process is based on Tompkins (2008). Therefore, through these stages, students are expected to master their writing skill better after going through the Wiki-based collaborative writing in this particular study.

\section{The relationship of Wiki-based collaborative writing with Vygotsky (1978) Constructivism Theory}

According to Hewett (2009), in writing aspect constructivism theory involves collaborative learning where students need to participate and communicate with each other and this shows that knowledge is developed with individuals of the same groups and shared similar norms and belief. Therefore, in this research, the researcher adapts this theory in designing the platform of Wiki based collaborative writing. First of all, the researcher will select the respondents based on their proficiency level, which are students of high proficiency level in English as well as students of low proficiency in the language. Students' proficiency level will be determined based on their Form 1 end year examination result. It is important to emphasize that the variation in language proficiency encourage scaffolding among learners which meet the aim of applying constructivist model and having collaborative writing tasks. This is justified as according to Yellan and Masters in Li, Chu and Woo (2012), scaffolding among learners encourages development of cognitive, motivation, and lower the affective factors among students. Thus, by looking closely at the upper part of the conceptual framework in figure 1.1, it can be said that, the framework for this study supports the application of social constructivist theory where the Wiki based writing atmosphere is conducted in the collaborative context.

Based on Witts (2011), Wiki permits users to exchange ideas, opinion and thoughts as well as revising content and comments based on their knowledge through online interaction. Besides, in collaborative writing, students need to undergo several stages which are prewriting, drafting, revising, editing, and publishing ( $\mathrm{Li}, \mathrm{Chu}, \mathrm{Ki} \&$ Woo, 2012). Therefore, this is the part where the social constructivist theory is implemented in the study. Moreover, the theory itself highlights that knowledge acquisition is the product of social interaction. In the present study, students of different proficiency level will work collaboratively to complete writing task in a particular Wiki webpage provided for them. Therefore, interaction as well as communication existed between the respondents through the act of revising, commenting, as well as editing each other's work. Although the Wiki serve as a platform for student centred learning, $\mathrm{Li}, \mathrm{Chu}, \mathrm{Ki}$ and Woo (2012), states that, the roles of the teachers to provide instructions and guideline is very important to facilitate as well as to keep the students on track. Hence, the implementation of Wiki-based writing lesson will provide better learning environment where students are actively participate in conducting discussions. This agrees with Almala (2006) who proposes that online interaction and communication encourage successful negotiation medium between students.

With reference to $\mathrm{Li}$, Chu, and Woo (2012), the Wiki-based writing environment as well as the collaborative writing process is supported by the social view of writing process (Faigley, 1986; Tompkins, 2008). Generally, the social constructivist theory of composition incorporates collaborative writing in English classroom Hewett (2009). This theory suggests on the significance of the social context and shared belief the community as the base of cognitive development where knowledge is acquired through social group. According to Faigley (1986) the social perspective of writing process is common in the collaborative writing pedagogy as the central view of this theory is writing is considered as conversation in a particular discourse community. Since the students in this research interact and communicate with each other in the Wiki pages, the present cannot neglect the important perspective proposed by this theory. This is supported by Tompkins (2008) who proposes that collaborative writing is closely related to the social view of writing because the process of writing represents students' thoughts which consists of the prewriting, drafting, revising, editing, and publishing phases.

Therefore, by implementing the use of Wiki-based collaborative writing in English language classroom, the present research will be done to develop ESL learners' interest as well as performance in writing through the use of Wiki in English language lesson. This is good as according to Tompkins (2008), students are more prepare and ready for independent writing after they have gone through the processes involved in collaborative writing through Wiki based on the social constructivist theory as well as the social view of the writing process theory. 


\section{Integrating the use of Wiki in ESL writing classroom}

The first research which has a close relationship with the subject is by Nazatulshima (2006) which stated that the use of computer technology is developing due to the increasing number of software created for educational purposes. In addition, Judd, Kennedy and Cropper (2010) mention that Wiki is a getting more and more popular among students and teachers in the education atmosphere. Basically it acts as collaborative writing equipment which encourages self-learning and achievement among the students. Since Wiki is one of the web 2.0 tools, it has been enlisted as the current trend which is incorporated in language lesson to enhance the process of learning and teaching (Hughes, 2009; Kennedy et al (2009). Not only that, Bower, Woo, Roberts and Watters (2006) as well as Bruns and Humphreys (2007) suggest that, Wiki is particularly popular and it serves as an interactive website that can be edited, reviewed as well as revised by several people through the use of some user-friendly page tools. Due to this circumstance, the concept of Wiki is surprisingly applicable towards the language classroom context as it provides variation in terms of the teaching material being introduced by the teacher. Besides, Arronson (2002) adds that Wiki is also a base for E-learning which supports collaborative learning experience among students. In short, this is the feature which makes Wiki more fascinating to be applied in writing classroom (Arronson, 2002; and Leuf \& Cunningham, 2004).

It is important to emphasize that the use of Wiki certainly encourages collaborative learning among students (users). This is because Wiki is designed to be utilized by more than one person, and each individual will be helping each other in the revising process to expand the content by providing information, attaching files or documents, or creating links to enhance understanding of each student on certain topic (Morgan \& Smith, 2008). Thus collaboration among students whether they are of high or lower proficiency in the language exists within interaction and communication through Wiki. This is proven where Wiki has the potential to encourage constructivist teaching and learning atmosphere as it facilitates the social construction as well as reconstruction of the content of knowledge (Li, Shi, \& Tang, 2012). Therefore through the collaborative feature that Wiki serves, it is expected that supportive learning among students can be encouraged and this will help them to improve their writing skills especially to produce better essays.

Other than that, Wiki can also be used upon the wide range of the second language learner to develop their language acquisition. Although it seems a bit sophisticated, the process of language learning can be applied to all students of different proficiency in the language. This is true as according to Wang (2005) the use of Wiki provides a lot of advantage towards the beginner level of students as it encourages their motivation and willingness to learn. Besides, Robinson (2006) in Deters, Cuthrell and Stapleton (2010) suggest that Wiki is an effective tool for teachers as well as educators. This is because it allows users to quickly update the content of the webpage which make it more fascinating. This simple feature gives a sense of uniqueness to the Wiki which make it flexible and applicable to be used by educators and students of different levels (Bold, 2006). Not only that, a research by Franco (2008) found that through the use of Wiki, learners are more interested in learning the language as well as it develop the social skill among students. The next study was done by Larusson (2010) which describes the use of Wiki Design Platform (WDP) in supporting collaborative writing among ESL learners. Specifically, this research highlights Wiki as a platform to build up collaborative interaction which allows users to facilitate each other in learning to write. The evidence from the research findings shows that Wiki provides the best medium to support online collaborative learning and teaching experience for both teacher and students. Besides, this research discovered that, Wiki helps learners to undergo metacognitive task as well as activities which help to enhance language learning. A research has been carried out by $\mathrm{Li}, \mathrm{Chu}, \mathrm{Ki}$ and Woo (2012) among 59 standard four students in China. The research practices the approach of Wiki-based collaborative writing as a platform to encourage students' writing skill. In addition, the study is conducted to measure students' performance, as well as motivation towards using Wiki as a method to teach writing lesson. The Wiki that has been set is given a name of Joyous Writing Club (JWC) which has been developed by online Wiki software which is MediaWiki. Basically, the research instruments for this study are observation, questionnaire, interviews as well as reflection. The results of this study illustrate positive effects of using Wiki in language classroom as it encourages motivation in writing, interaction as well as writing performance. 
The next research that has been reviewed by the researchers is by Deter et al. (2010). In this research, the emphasis was given to the use of Web 2.0 tools especially Wiki as one of the new method to be brought in the classroom environment. This study involves 40 students of social study course and the focus was on students' perception towards the use of Wiki in online instruction and its potential to be used in the classroom environment. The data for this research was collected by using surveys as well as written reflection. Although there are some conflicts while conducting the Wiki-based learning in the study, the overall perception on Wiki among students is encouraging and positive. In a way, it can be described that, in previous studies Wiki serves as the best platform of learning to write in English due to its feature which allows collaborative writing among learners. Besides, it can also be said that Wiki helps to produce nonthreatening classroom experience.

\section{Participants of the Study}

This research involves purposive sampling where participants were selected from a government aided secondary school. Specifically, nine respondents from a form 2 class were chosen to participate in this research. All of the participants were 14 years old. Basically, students in a form 2 class of this school were chosen because of their proficiency in using the language and their ability to voice out their opinion in the lesson. Since this research focuses on using Wiki as writing tool, it is important to insert the elements of collaborative learning among students. Therefore, the researcher had decided on using 3 participants of high proficiency in English, 3 participants with intermediate level of English proficiency, while the other 3 participants were those who are low proficient. The students' level of proficiency was categorized based on their grades in the Form 1 final English language examination. Specifically, participants who got 'A' grade in their form 1 English Language Examination is categorised as high proficiency participants, those who got ' $\mathrm{B}$ ' grade is intermediate level of student, while participants with ' $\mathrm{C}$ ' grade fell under low proficient category. It is hoped that, students will help each other during the process of writing and student centred learning experience can be created. Moreover, through this way the pattern of the social constructivist theory in collaborative writing can be clearly seen. Most of all by selecting these particular participants, the effect of using Wiki to improve ESL learners' writing skill can be measurable simply by looking at the students' performance after the treatment.

\section{Research Procedure}

This research started with a pre-test where participants were asked to write an essay to be assessed. The aim of this pre-test was to identify students' performance of their essay writing before they underwent the treatment sessions. During the treatment sessions, participants used Wiki as a mean for collaborative writing with the purpose of having an interactive writing lesson experience which serves as a platform to collaborate and prepare them with better writing skill. Participants spent eight hours, which were divided into four sessions participating in the collaborative writing during the treatment session. Later, all the participants had to attend to a post-test as to again identify their performances in their essay writing. Early in the first time of meeting, the researchers provided the students with the login IDs (email address) and password to set up their own email address that were used as identification to join the Wiki website. It is needed to be emphasized here that providing the respondents with Wiki IDS is significant to reduce the hassle faced by both respondents and researchers in terms of time as well as technological related problems. Since the website is in private mode, students will not be able to view the content unless they are added as the member of the group. Next, the Wiki platforms were set up for them by registering each of the students according to small Wiki group of three. The researchers used ZOHO wiki webpage to serve as the medium to encourage students writing skill as well as to introduce the collaborative writing experience among students. After signing in as the main administer to the web, the researchers created several pages as a channel to deliver messages, information, interaction as well as instructions to the students. Specific name, task, as well as week number were written in each of the page in the website to make it more user-friendly. After that, an ice-breaking session was done between the researchers as well as the students by the use of ZOHO Wiki to familiarize themselves to the tools and application that can be integrated in the Wiki pages. Thus, as they are familiar with the interface and layout of the Wiki, the flow of the treatments will not be interrupted due to several technical difficulties. 
Writing assessment (Pre-Test and Post-Test)

The writing assessments which are the pre-test and post-test were carried out to examine the effect of using Wiki towards the participants' performance in writing, specifically essay composition. Basically, students have undergone two writing tests before and after the treatment session. Both pre-test and post-test required them to write descriptive essays on topics which have been selected by the researchers. It is important to be emphasized here that the topics selected for the tests are based on the curriculum specification provided by the Ministry of Education for Form 2 students as the participants selected were all from the government aided school. Then, the essays were evaluated by an experienced secondary school teacher using a rubric which is designed as marking guidelines for government aided school. The rubric guidelines were prepared by the Malaysian Examination Syndicate (MES) and approved by the Ministry of Education (MOE). By this way, the validity and reliability of the assessments' scores can be assured.

\section{The implementation of Wiki as a platform for collaborative writing}

In particular, the treatment duration was two weeks. Basically; two sessions of Wiki-based collaborative writing activities were conducted in each of the week where the lengths are approximately two hours per session. Thus, the total of 8 hours treatment is given to prepare the students with the appropriate knowledge to develop their writing skill via the implementation of Wiki in language lesson. Each treatment session requires the students to undergo different writing activities which need them to collaborate with each other in completing certain tasks. It is need to be emphasized that the present research focuses on the students' progress and development in writing essay.

In the first session, the researcher introduced the students with the simple and compound types of sentence based on the curriculum specification of form 2. Besides, the steps of constructing sentences by following the rules of subject-verb-agreement were also highlighted. Since the students are already in form two, it is expected that they already have background knowledge about sentence types and structure. Due to this circumstance, students were given some practices to strengthen their ability in constructing sentences. As the treatment sessions over, students have undergone a post-test in the fifth week. Once again they need to write an essay individually. The post-test question was the same as the pre-test where it was given to them based on the syllabus or curriculum specification for Form 2 students. The time allocated to finish the essay is one hour and the word count should be more than 120 words, based on the PMR standard. After that, the pre and post-test essays of the students were evaluated by experienced teacher who has been teaching for 7 years at secondary school in Johor and the evaluation is according to rubric by Malaysian Examination Syndicate (MES). Then, the result was evaluated based on the students' performance and achievement.

Since Wiki deals with the aspect of collaborative writing, students worked collaboratively to complete the tasks given through prewriting, drafting, revising process, as well as the final touch which is editing the essay. In this part, students are expected to provide peer feedbacks through comments or during online interaction by correcting errors and mistakes on the elements of sentence structure (subject-verbagreement). Nevertheless, students are encouraged to revise on other relevant linguistic components as well. As Wiki allows users to edit and revise each other's contribution in the webpage, students of high proficiency were expected to facilitate low proficient students by providing comments as well as advice on the errors that they have done. In a way, learner centred learning as well as scaffolding among students can be created.

\section{Data Analysis and Discussion}

The analysis of data for writing assessment (per-test and post-test) was done by looking at the marks scored by each of the respondent before and after the treatment. The scores were tabulated so that it is easier for the reader to compare the students' performance after the implementation of Wiki in writing lesson. Based on the gathered data, the increments was well as declining marks in essay writing were documented to figure out to what extent does Wiki helps to enhance ESL learners' performance in writing better English language essays. Besides, the researchers have also analysed the respondents' essays in both tests, and compared them in terms of students' sentence structure which mainly about the rules of SVA which this study has focused on. In a way, students' development in writing skill after the use of Wiki can be monitored, encouraged and measured. The respondents consist of mainly female students which bring 
about $66.6 \%$ of the total amount of students. Thus, the remaining $33.3 \%$ are male respondents which can be considered as the minority group in this research. The respondents come from different races. Generally, Malay students represent about $44.4 \%$ from the total number of respondents. This is followed by Chinese students which are about $33.3 \%$ as well as the remaining $22.2 \%$ represents the Indian respondents.

As the concern of this research is to examine whether Computer-Supported Collaborative Writing works among ESL learners, thus the researcher had selected samples of sentences from respondents' essays in Pre- Test as well as Post Test to examine the differences. In doing so, the researcher chooses sentences of the same ideas so that the pattern of sentence construction can be easily identified. In particular, the focus of this study is only on one aspect of linguistic form which is the Subject-Verb-Agreement (SVA).

It is important to recognize the improvements in students' achievement during the tests by comparing the respondents' results before and after treatments. As mentioned before, the focus of the research will only be given to the rules of Subject-Verb- Agreement (SVA) which acts as a benchmark to see whether or not students are capable to develop better essay and writing skill. Table 1 summarizes the respondents' achievements in both pre-test and post-test.

Table 1: The comparison of achievement in the pre-test as well as post-test for each respondent

\begin{tabular}{|c|c|c|c|c|}
\hline Wiki group & Student & Students' Proficiency Level & Pre-test scores & Post-test scores \\
\hline 1 & $\mathrm{~A}$ & High & 18 & 22 \\
\cline { 2 - 5 } & $\mathrm{B}$ & Intermediate & 14 & 18 \\
\cline { 2 - 5 } & $\mathrm{C}$ & Low & 9 & 12 \\
\hline 2 & $\mathrm{D}$ & High & 20 & 23 \\
\cline { 2 - 5 } & $\mathrm{E}$ & Intermediate & 16 & 20 \\
\cline { 2 - 5 } & $\mathrm{F}$ & Low & 10 & 13 \\
\hline 3 & $\mathrm{G}$ & High & 19 & 23 \\
\cline { 2 - 5 } & $\mathrm{H}$ & Intermediate & 15 & 19 \\
\cline { 2 - 5 } & $\mathrm{I}$ & Low & 11 & 15 \\
\hline
\end{tabular}

Table 2 shows all of the participants in this research had positive improvements in their writing score after the treatments with an increment of the score ranges between 3 to 4 points. Basically, all of the respondents begin to understand the concept of SVA where they produce sentences with appropriate grammar structure and forms. Take the case of respondents A, D and G. By looking at the way of constructing sentences in the assessments, the students can be regarded as having full understanding on how to use correct SVA rules in the composition after the treatment. The following samples of students' sentence production were extracted from their pre-test as well as post-test essay.

Table 2: Students' sentence production from pre-test and post-test essay

\begin{tabular}{|c|l|l|}
\hline Respondent & Pre-test & Post-test \\
\hline A & $\begin{array}{l}\text { During my school holidays, my father decide to } \\
\text { bring us to have a picnic in Pantai Port Dickson. }\end{array}$ & $\begin{array}{l}\text { On last week Sunday, my father brought all of } \\
\text { the family members to go out for picnic in } \\
\text { Gunung Ledang, Johor. }\end{array}$ \\
\hline D & $\begin{array}{l}\text { The accident tell me about we must cautions when } \\
\text { we are driving on the road or... }\end{array}$ & $\begin{array}{l}\text { The scary and horrible accident reminded me that } \\
\text { we need to be careful and fresh if we want to } \\
\text { drive our car using the highways. }\end{array}$ \\
\hline G & $\begin{array}{l}\text { Last week, I am so happy as well as excited during } \\
\text { the journey to Pantai Klebang because I like to } \\
\text { spend free time with family and friends. }\end{array}$ & $\begin{array}{l}\text { I was so cheerful and enjoy my trip to Melaka } \\
\text { during the school break two weeks ago. }\end{array}$ \\
\hline
\end{tabular}


It can be said that respondents $\mathrm{A}, \mathrm{D}$, and $\mathrm{G}$ possess wide range of vocabulary where he or she can shift the words used according to the suitability in the sentence context. This means that, they do not have to stick around with the same word to express the content of writing and to develop ideas. Plus, all the three of them are categorised as students with excellent proficiency in English language. In a way, they have more input on the second language compared to other respondents who might not. Indirectly, this shows that the use of Wiki enriches their understanding and develops better writing skills among them since the students are helping each other in rectifying errors and mistakes (Cress \&Kimmerle, 2008).

Since this research concern on the main feature of Wiki which promotes collaborative writing, it can be said that, most of the respondents and teacher mutually benefit from it. This is because not only advance students, but the intermediate and low proficient students exhibit affirmative development in writing. Particularly, respondents B, C, E and F simplified their sentence structure which makes the meanings of the sentences clearer and comprehensible by the readers. Consider the sentences derived from the students' essay as seen in Table 3.

Table 3: Pre-test and post-test sentence production

\begin{tabular}{|c|l|l|}
\hline Respondent & Pre-test & Post-test \\
\hline B & $\begin{array}{l}\text { On Previous Monday, my uncle and I want to went to } \\
\text { Kuala Lumpur to visit my grandfather }\end{array}$ & $\begin{array}{l}\text { Last week, my family and I went to the } \\
\text { zoo in Johor Bahru. }\end{array}$ \\
\hline C & $\begin{array}{l}\text { Last Sunday, auntie Tina and uncle Ridhuanbring me to } \\
\text { shopping at the PasarayaSakan in Segamat area. }\end{array}$ & $\begin{array}{l}\text { During the school holiday, my uncle } \\
\text { brought me to go to BatuPahat city. }\end{array}$ \\
\hline E & $\begin{array}{l}\text { We got out from the car and went to see what had } \\
\text { happening across the road. }\end{array}$ & $\begin{array}{l}\text { All of us looked at the accident from the } \\
\text { window in our car. }\end{array}$ \\
\hline F & $\begin{array}{l}\text { Last week Saturday, there is an accident were helding on } \\
\text { North South highway at 2.30 PM. }\end{array}$ & $\begin{array}{l}\text { In school holiday, there was accident } \\
\text { happening on North South Highway. }\end{array}$ \\
\hline
\end{tabular}

Based on the excerpts of the respondents' sample of sentences, the grammatical rule of SVA that they use is accurate. Thus, it can be said that, through all the treatments given to the respondents through Wiki mediated collaborative learning, students develop peer feedback, scaffolding as well as independent learning which results in better awareness of constructing grammatical sentences and essays (O'Neill, 2005).

In particular, the researcher would say that student $\mathrm{H}$ shows great improvements in producing better essay and creating good sentences. Basically, he come out with meaningful and a good written discourse specifically on the use of SVA. Not only that, the respondent do not stick with his previous sentence but rather, he comes out with new lexical choice with the correct selection of tenses according to the essay's context. As for reference, consider the following sentences sample by the subject (Respondent $\mathrm{H})$ :

Respondent $\mathrm{H}$ :

$$
\begin{array}{ll}
\text { Pre - Test: } & \begin{array}{l}
\text { I will also reminded my relatives be more careful } \\
\text { when use highway. }
\end{array} \\
\text { Post - Test: } & \begin{array}{l}
\text { I advised my friends, family and relatives so that } \\
\text { they will be caution when they use the highway. }
\end{array}
\end{array}
$$

By looking closely, this situation reflects on the factors which affect students' performance in writing. The students' achievements can be seen developed by different ways or perspectives. It depends on the teachers' efforts and creativity to encourage and enhance improvements in their performance. In this case, the researcher found that, computer-supported collaborative writing such as Wiki does work among the ESL participants in stimulating interest in learning to write better essays and somehow it boosts up their accomplishment in language classroom.

\section{Pedagogical implications}

First of all, it is needed to be emphasized that Computer-Supported Collaborative Writing that is using Wiki in this case, has helped teachers to create an independents classroom learning environment. Thus, the teachers' responsibility is to encourage the students to do some editing and revising process by providing 
peer feedbacks and scaffolding which will lead to better teaching and learning environment. Nevertheless, teachers will always need to be aware of the learning process by monitoring each feedbacks and comments among the students so that there will not be any misunderstanding or misconceptions on the language forms and structure during the scaffolding process (Scardamalia\&Bereiter, 2006). In addition, Leung and Chu (2009) have also highlighted that teachers should play active roles during the E-learning session to avoid the students from doing last minute work which will inhibit the acquisition of language skills.

Other than that, it will be very beneficial if teachers can encourage the students to write collaboratively during the learning process. In a way, collaborative writing allows the students to be more critical and analytical where they have to think of the way how to generate ideas and link it together based on different people opinion. Finally, it is good to clarify that, the use of Wiki should be implemented in the language classroom as it provides new insights for both teacher and students to a more resourceful and authentic learning materials and approaches which are totally different with the traditional classroom practices. In particular, providing genuine collaborative classroom environment enhances meaningful communication and discussion that increase cooperation among students (Miers, 2004).

Since Wiki's main feature is to implement collaborative writing and learning, all of the students need to cooperate with each other to finish the task. As Wiki allows users to edit and revise each other's contribution in the webpage, students of high proficiency were expected to contribute more.

\section{Significance of the Study}

The findings from this research are very important, valuable and useful towards the development of the education field, especially the English language society in Malaysia. This is because, through the findings, more advantages on the implementation of CALL in language classroom can be highlighted. Other than that, the potential which Wiki provides in generating better teaching and learning of writing will also enhance teachers' awareness on the importance of creating new teaching materials and methodologies in language classroom rather that utilizing the same traditional teaching style. Furthermore, through the findings, it is hoped that ESL learners and teachers are encouraged to produce independent learning atmosphere which enhance students' active participation in the classroom. Besides, student centred learning through collaborative writing can be created to train the students to be more active, motivated as well as confident in voicing their ideas as well as opinion in the learning process. Most of all, by bringing a new classroom environment, students' interest and enthusiasm to learn to write will certainly be enhanced and developed.

Indeed, the implementation of CALL based learning in ESL context enables teachers as well as students to experience new approach of learning. Somehow or rather, the suitability of the computer based learning is sometimes restricted due to time constraint as well as the examination oriented environment of learning English in the ESL context. This is true as according to Hiep (2007), most of the students in Asian context pay more attention of passing the examination rather than understanding the input of the language well. Thus, in order to make the learning process more meaningful, teachers should put more effort to get the students to participate well in the lessons.

Based on the researcher's point of view, it is important that teachers implement the use of Web 2.0 tools in the language classroom to enhance students' active participation during the English language lessons. This is because, research conducted by Mak and Coniam (2008) highlight that the implementation of Web 2.0 tools especially the Wikis produce students with better writing production through collaborative stages. Besides, it is also very useful if teachers can exploit and develop more learning activities with the integration of computer tools to enhance students' interest and motivation in the classroom better. On the other hand, for future research, it is suggested that developing the study in other context and disciplines can explain more benefits and advantages of using Wiki for learning purpose. Besides, researchers can also investigate on how the different type of contribution in the collaboration process affect students' acquisition of language and learning skills. Finally, it is also interesting if students can provide intergroup peer feedback rather than in group collaboration as applied in this study. In a nutshell, the implementation of Wiki for collaborative writing in language classroom brought a new teaching pedagogy which supports the development of students' proficiency in English. 
IR A-International Journal of Education छ Multidisciplinary Studies

\section{Conclusion}

The present study aimed to examine whether Computer-Supported Collaborative Writing works among ESL learners, specifically to investigate the effect of using Wiki based collaborative writing towards ESL learners' writing performance. In order to investigate on this matter, the researcher has conducted writing assessments (Pre-Test and Post-Test) to evaluate learners' development in writing English language composition. Specifically, the respondents indicate positive increment of essay scores in the post test where the range of increased marks is between 3 to 4 points. Obviously, Wiki leads to the development of students' ability in essay writing since the marks allocated represent the whole components of essay organization by the Malaysian Examination Syndicate writing rubrics, where it consists of the aspect of (1) ideas development, (2) sentence structure, (3) mechanics, as well as (4) essay organization. Specifically, the second research question for this study is answered as Wiki provide a medium of scaffolding which help learners to acquire better performance in writing essays. Moreover, Ryan (2007) has also proposed that integrating online collaborating learning tools support and build students' achievement in language classroom.

Based on the findings, it can also be said that students are not only improving in terms of their performance in essay writing, but also, they build up better writing skills. It is proven as there is a slight development in the way they construct sentences through appropriate use of SVA rules. Somehow or rather, the aspect of sentence structure does give impact towards students' writing performance. Therefore, it is suggested to the teachers that providing the students with explicit linguistic form and functions in writing help them to better understand the language rules. This agrees with Kim et al. (2009) and Trentin (2009) who proposed that collaborative writing through Wiki provide chances for students to develop academic writing ability.

As for the last challenge related to the collaborative feature of Wiki is about the respondents' contribution throughout the treatments. Since, the researchers play role as the main administrator of all the Wiki websites used by the students for collaborative writing, all respondents' activities from the beginning to the end can be easily monitored. According to the Wiki log in each website, the respondents, regardless of their proficiency level, are fond of revising their Wiki with non-language related contribution. Generally, this includes revising the fond size, uploading pictures, changing the Wiki background and other activities to get their Wiki appear beautiful and creative compared to other groups. However, language related contribution such as editing the sentence structure, revising appropriate synonyms or vocabulary, as well as rectifying grammar errors are not frequently done by the students. In the researchers' point of view, students should be encouraged to revise and edit certain linguistics aspects which they think appropriate to show that they understand on how the language forms and functions work. In addition, revising the linguistic aspect will also help them to perform better in acquiring the second language. Although this research is conducted based on the previous research related to the topic, this study does not represent for a wider and larger research respondents as participants possess different learning aptitude, learning strategies as well as dissimilar learning context. Since the present study is a small scale research done on 9 ESL of a secondary school, the findings cannot be generalised to other second language classroom. Not only that, small sample size restricts interactions as well as the learning process might be in a very minimal level (Violet \& Mansfield, 2006). The second limitation of the research is on the aspect of time constraint. In particular, the treatment sessions that have been conducted among the students are very short. In order to get an appropriate measurement of students' performance, longer treatment process is required so that students are mentally and physical prepared for writing assessments. Then, it can be said that although all of the respondents are IT savvy and familiar enough with the use of computer, bringing the ICT tools in the classroom can also be devastating for the students since they are not very familiar with this kind of learning environment. Therefore, they might be anxious with the learning process as it is totally different with the conventional classroom atmosphere. The next limitation will be on the notion of cooperative and collaborative writing. Basically, it is very important for instructors as well as the students to understand the concept of collaborative writing which is the default feature of Wiki. 
IRA-International Journal of Education $\Xi^{0}$ Multidisciplinary Studies

\section{Acknowledgement}

The authors are very grateful to the teacher and the students of a secondary school in Malaysia for their participation in the study reported in this paper. We would also like to thank Universiti Teknologi Malaysia and the Ministry of Education, Malaysia for granting the permission to conduct this research.

\section{References}

[1] Al-Buainain, H. (2011). Students' Writing Errors in EFL: A Case Study. QNRS Repository, 2011(1).

[2] Almala, A. H. (2006). Applying the principles of constructivism to a quality e-learning environment. Distance Learning, 3(1), 33.

[3] Aronsson, L. (2002, November). Operation of a Large Scale, General Purpose Wiki Website. In Elpub.

[4] Ashman, A., \&Gillies, R. (Eds.). (2003). Cooperative learning: The social and intellectual outcomes of learning in groups. Routledge.

[5] Bold, M. (2006). Use of wikis in graduate course work. Journal of Interactive Learning Research, 17(1), 514.

[6] Bower, M., Woo, K., Roberts, M., \& Watters, P. (2006, July). Wiki pedagogy--a tale of two wikis. In 2006 7th International Conference on Information Technology Based Higher Education and Training (pp. 191202). IEEE.

[7] Boyd, S. (2003). "Are you ready for Social Software?" Darwin Magazine. In Gonzalez-Reinhart, J., Wiki and the Wiki Way: Beyond Knowledge Management Solution, Information Systems Research Center, University of Houston, TX.

[8] Bragg, A.B. (2007). Reflections on pedagogy: Reframing practice to foster informal learning with social software. Retrieved September 26, 2008 from http://matchsz.inf.elte.hu/TT/docs/Anne20Bartlett-Bragg.pdf

[9] Brown, J. D. \& Rodgers, T. S. (2003). Doing second language research. Oxford: Oxford University Press.

[10] Bruns, A., \& Humphreys, S. (2007, October). Building collaborative capacities in learners: the M/cyclopedia project revisited. In Proceedings of the 2007 international symposium on Wikis (pp. 1-10). ACM

[11] Chin, J. A. (2012). The Challenge of Using Wikis in School: The Experiences of Two Grade Six Teachers. Published Ph.D. dissertation. Queen's University, Kingston, Ontario, Canada.

[12] Cress, U., \&Kimmerle, J. (2008).A systemic and cognitive view on collaborative knowledge building with wikis. Computer-Supported Collaborative Learning, 3, 105-122.

[13] Deter, F., Cuthrell, K., \& Stapleton, J. (2010). Why wikis? Student perceptions of using wikis in online coursework. MERLOT Journal of Online Learning and Teaching,6(1), 122-134. Retrieved from http://jolt.merlo t.org/vol6no1/ deters_0310.pdf

[14] Faigley (1986) \& Tompkins (2008) in Li, X., Cu, K. W., \& Woo, M. (2012). Using a wiki-based collaborative process writing pedagogy to facilitate collaborative writing among Chinese primary school students. Australian Journal of Education Technology, 28 (1), 159-181.

[15] Faigley, L. (1986). Competing theories of process: A critique and a proposal. College English, 48(6), 527542.

[16] Farkas, M. (2008). Technology in Practice: CMS the Wiki way. American Library Association, 39 (11), 35.

[17] Feuerstein, R. (1990). The theory of structural cognitive modifiability. National Education Association.

[18] Hewett (2009) in in Li, X., Cu, K. W., \& Woo, M. (2012). Using a wiki-based collaborative process writing pedagogy to facilitate collaborative writing among Chinese primary school students. Australian Journal of Education Technology, 28 (1), 159-181.

[19] Hewett (2009) in Li, S., Shi, P., \& Tang, Q. (2012). A case study on scaffolding design for Wiki-based collaborative writing.

[20] Hiep, P. H. (2007). Communicative language teaching: Unity within diversity. ELT journal, 61(3), $193-201$.

[21] Hughes \& Kennedy et al, (2009).in Judd, T., Kennedy, G \& Cropper, S. (2010). Using Wikis for collaborative learning: Assessing collaboration through contribution. Australasian Journal of Educational Technology. 26 (3), 341-354.

[22] Judd, T., Kennedy, G., \& Cropper, S. (2010). Using wikis for collaborative learning: Assessing collaboration through contribution. Australasian Journal of Educational Technology, 26(3), 341-354.

[23] Kim, P., Hong, J.-S., Bonk, C., \& Lim, G. (2009). Effects of group re flection variations in project based learning integrated in a Web 2.0 learning space. Interactive Learning Environments, 14 (3), 1-17.

[24] Larusson, J. A. (2012). Supporting the "collaborative" part of wiki-mediated collaborative learning activities. Published Ph.D. dissertation. Brandeis University, Waltham, Boston.

[25] Leuf and Cunningham (2010) in Deters, F., Cuthrell, K., \& Stapleton, J. (2010). Why wikis? Students' perceptions of using wikis in online coursework. MERLOT Journal of Online Learning and Teaching, 6(1), 122-134. Retrieved from http://jolt.merl ot.org/vol6no1/deters_0310.pdf

[26] Leuf, B. \& Cunningham, W. (2001).The wiki way: Quick collaboration on the Web. Upper Saddle River, NJ: Addison Wesley. 
[27] Leung, K., \& Chu, S. K. W. (2009).Using wikis for collaborative learning: A case study of an undergraduate students' group project in Hong Kong. http://ww w.ickm2009.org/snews/upload/ickm_2009.

[28] Levy and Stockwell (2006) in SafynazKazem. (2010). Collaborative story writing using wikis among postgraduates. Unpublished master dissertation, University Teknologi Malaysia Johor Bahru, Malaysia

[29] Levy, M., \&Stockwell, G. (2006). Call dimension: Options and issues in computer assisted language learning. London: Routledge

[30] Li, X., Cu, K. W., \& Woo, M. (2012). Using a wiki-based collaborative process writing pedagogy to facilitate collaborative writing among Chinese primary school students. Australian Journal of Education Technology, 28 (1), 159-181.

[31] Mak, B., \&Coniam, D. (2008). Using wikis to enhance and develop writing skills among secondary school students in Hong Kong. System, 36, 437-455.

[32] Miers, J. (2004). BELTS or Braces? Technology School of the Future. Retrieved from http://www.tsof.edu.au/research/Reports04/miers.asp

[33] Morgan, B., \& Smith, R. D. (2008). Technology in Literacy Education: A Wiki for Classroom Writing. The Reading Teacher, (62) 80-82. Retrieved from http://www.jstor.org/stable/20204663.

[34] Nagin, C. (2003). National Writing Project. Because Writing Matters: Improving Student Writing in Our Schools.

[35] NazatulshimaMustafar. (2006, April). The use of computer assisted language learning (call) courseware in learning literature: A case study of form four student of SekolahMenengahDato' Penggawa Barat, Pontian, JohorDarulTakzim. Website: http:// www.fp.utm.my/e PusatSumber /pdffail/ptkghdfwP/NAZATULSHI MAAP010249D2006TTP.pdf

[36] O'Neill, M.E. (2005). Automated use of a wiki for collaborative lecture notes. Proceedings of the $36^{\text {th }}$ SIGCSE Technical Symposium on Computer Science Education, St. Louis, Missouri, USA: February 23-27, 267-271. Retrieved from http://portal.acm.org/citation.cfm?id=1047440

[37] Robinson, M. (2006). Wikis in education: Social construction as learning. The Community College Enterprise, 107-109.

[38] Ryan, R. (2007). The Effects of Web-Based Social Networks on Student Achievement and Perception of Collaboration at the Middle School Level. Ph.D. Dissertation, Touro University International, California.

[39] Scardamalia, M., \&Bereiter, M. W. (2006). Knowledge building: Theory, pedagogy, and technology in K. Sawyer (Ed.), Cambridge handbook of the learning sciences (pp. 97-118). New York: Cambridge University Press.

[40] Tompkins (2008), in Li, S., Shi, P., \& Tang, Q. (2012). A case study on scaffolding design for Wiki-based collaborative writing.

[41] Trentin, G. (2009). Using a wiki to evaluate individual contribution to a collaborative learning project. Journal of Computers Assisted Learning, 25, 43-55.

[42] Violet, S., \& Mans field, C. (2006). Group work at university: Significance of personal goals in the strategies of students with positive and negative appraisals. Higher Education Research \&Development, 25 (4), 341356.

[43] Vygotsky, L. (1978). Interaction between learning and development. Readings on the development of children, 23(3), 34-41.

[44] William, M., \& Burden, R. L. (1997).Psychology for language teachers. Cambridge: Cambridge.

[45] Winkler, A.C., \&McCuen, J.R. (1997).WRITING TALK: Sentences and paragraphs.

[46] Witts (2011) in Li, X., Cu, K. W., \& Woo, M. (2012). Using a wiki-based collaborative process writing pedagogy to facilitate collaborative writing among Chinese primary school students. Australian Journal of Education Technology, 28 (1), 168-181.

[47] Wood, D., Bruner, J. S., \& Ross, G. (1976).The role of tutoring in problem solving. Journal of child psychology and psychiatry, 17(2), 89-100.

[48] Yunus. (2007) in SafynazKazem. (2010). Collaborative story writing using wikis among postgraduates. Unpublished master dissertation, University Teknologi Malaysia Johor Bahru, Malaysia. 